\title{
Mesenchymal stem cells in autoimmune diseases: hype or hope?
}

\author{
Hans U Scherer ${ }^{1,2}$, Melissa van Pel ${ }^{3}$ and René EM Toes ${ }^{* 1}$ \\ See related research by Schurgers et al., http://arthritis-research.com/content/12/1/R31
}

\begin{abstract}
Intervention with mesenchymal stem cells (MSCs) represents a promising therapeutic tool in treatmentrefractory autoimmune diseases. A new report by Schurgers and colleagues in a previous issue of Arthritis Research \& Therapy sheds novel mechanistic insight into the pathways employed by MSCs to suppress T-cell proliferation in vitro, but, at the same time, indicates that MSCs do not influence T-cell reactivity and the disease course in an in vivo arthritis model. Such discrepancies between the in vitro and in vivo effects of potent cellular immune modulators should spark further research and should be interpreted as a sign of caution for the in vitro design of MSC-derived interventions in the setting of human autoimmune diseases.
\end{abstract}

\section{Immunomodulation by mesenchymal stem cells in vitro and in vivo}

Mesenchymal stem cells (MSCs) are multipotent progenitor cells that can be cultured from various adult and fetal tissues and that are capable of differentiating into multiple mesenchymal lineages including bone, cartilage, tendon, marrow stroma and adipose tissue [1]. Because of their unique regenerative potential, MSCs are considered a promising therapeutic modality for tissue regeneration and repair. Moreover, MSCs are thought to be critically involved in the formation of survival niches for memory $\mathrm{T}$ cells and $\mathrm{B}$ cells in the bone marrow, thereby regulating the size, stability and plasticity of immunological memory.

Awareness has additionally been raised by the finding that MSCs display immunomodulatory properties in vitro, as evidenced by their ability to inhibit T-cell proliferation. This inhibition affects the proliferation of $\mathrm{T}$ cells

*Correspondence: r.e.m.toes@lumc.nl

'Department of Rheumatology, Leiden University Medical Center, Albinusdreef 2, 2300 RC Leiden, The Netherlands

Full list of author information is available at the end of the article induced by alloantigens, mitogens and CD3-ligation. Moreover, MSCs have also been shown to inhibit the proliferation of $\mathrm{B}$ cells, and possibly the activity of natural killer cells. The molecular interactions responsible for these inhibitory effects observed in vitro are the subject of intense investigations and include the action of prostaglandin $\mathrm{E}_{2}$, nitric oxide, indoleamine 2,3-dioxygenase and programmed death ligand-1 [2].

Because of their potent inhibitory effects in vitro, MSCs have been used in several preclinical disease models, most often aiming to inhibit alloreactive immunity such as is observed in graft-versus-host disease (GVHD), and in transplantation models. Several studies have now shown that infusions of MSCs can be effective in controlling GVHD or in promoting engraftment and survival of allogeneic bone marrow cells. Opposing observations have also been reported, however, as injection of allogeneic MSCs has been shown to trigger allospecific immune responses in vivo resulting in graft rejection [3]. Therefore it is conceivable that the modulatory effects observed in in vivo transplantation models are not all mediated by immune suppression, but possibly also through other mechanisms. The latter are presently not known, but could include production of MSCderived cytokines capable of expanding alloreactive natural killer cells. Such natural killer cells can efficiently kill donor/host-derived professional antigen-presenting cells and thereby inhibit the induction of allo-specific T-cell responses $[4,5]$.

The observation that MSCs themselves can induce alloreactive T-cell responses indicates a discrepancy between in vivo findings and the immunosuppressive in vitro findings as also observed by Schurgers and colleagues. Although this is poorly understood, MSC-based interventions are already pioneered in the clinical setting and the first promising results have been reported in the context of human GVHD [6] and Crohn's disease [7].

\section{Mesenchymal stem cells in autoimmune rheumatic diseases}

Despite these promising results from transplantation settings, effects in preclinical autoimmune disease models 
are less coherent. Some studies report amelioration of arthritic symptoms in preclinical arthritis models, whereas other studies - such as that by Schurgers and colleagues - could not report beneficial effects or even describe a worsening of the disease course $[1,8]$. The latter could in part be related to the use of allogeneic MSCs, as it has been reported that the use of allogeneic cells - presumably through additional cytokine release as a consequence of the underlying allo response - leads to the exacerbation of arthritis [9]. Furthermore, direct comparison of these studies is hampered by the use of different MSC culture conditions in vitro, different tissues from which the MSCs are derived, and a variety of different administration schedules currently used in vivo. Moreover, studies on the phenotype of MSCs in bone marrow indicate that MSCs are a heterogeneous population comprised of subpopulations that differentially express a number of receptors to interact with immunecompetent effector cells. The ability of MSCs to modulate immune responses therefore probably depends, in part, on the composition of the starting population.

Despite our incomplete understanding of the mechanisms underlying these divergent results, and inspired by positive reports on the use of bone marrow-derived MSCs in the outcome of GVHD and transplantation engraftment without the observation of severe side effects associated with the infusion of MSC, the first studies in human autoimmune disease are already appearing [10,11]. Not unexpectedly, however, the clinical effects are not coherent.

\section{Concluding remarks}

The mechanisms underlying the possible in vivo immunomodulatory effects of MSCs remain a critical and unresolved question. By comparing side by side the effects of MSCs in vitro and in vivo, the study by Schurgers and colleagues brings fresh encouragement to the endeavors to elucidate the immunomodulatory effects of MSCs in rheumatic diseases [1]. Given the apparent difficulties in recapitulating the in vitro effects in vivo, however, researchers should be cautioned and should remain critical concerning the use of MSCs for the treatment of human autoimmune disease. It is likely that the endeavors will eventually pay off, but more experience with the use of MSCs in the setting of GVHD can help guide their use for rheumatic diseases, thereby certifying or revoking their therapeutic use for the control of autoimmunity.

\section{Abbreviations}

GVHD, graft-versus-host disease; MSC, mesenchymal stem cell.
Competing interests

The authors have no competing interests.

\section{Author details}

'Department of Rheumatology, Leiden University Medical Center, Albinusdreef 2, 2300 RC Leiden, The Netherlands. ${ }^{2}$ Department of Rheumatology and Clinical Immunology, Charité-University Medicine Berlin, Charitéplatz 1, 10117 Berlin, Germany. ${ }^{3}$ Department of Immunohematology and Blood Transfusion, Leiden University Medical Center, Albinusdreef 2, 2300 RC Leiden, The Netherlands.

Published: 18 June 2010

References

1. Schurgers E, Kelchtermans H, Mitera T, Geboes L, Matthys P: Discrepancy between the in vitro and in vivo effects of murine mesenchymal stem cells on T-cell proliferation and collagen-induced arthritis. Arthritis Res Ther 2010, 12:R31.

2. Nauta AJ, Fibbe WE: Immunomodulatory properties of mesenchymal stromal cells. Blood 2007, 110:3499-3506.

3. Nauta AJ, Westerhuis G, Kruisselbrink AB, Lurvink EG, Willemze R, Fibbe WE: Donor-derived mesenchymal stem cells are immunogenic in an allogeneic host and stimulate donor graft rejection in a nonmyeloablative setting. Blood 2006, 108:2114-2120.

4. Boissel L, Tuncer HH, Betancur M, Wolfberg A, Klingemann H: Umbilical cord mesenchymal stem cells increase expansion of cord blood natural killer cells. Biol Blood Marrow Transplant 2008, 14:1031-1038.

5. Shlomchik WD, Couzens MS, Tang CB, MCNiff J, Robert ME, Liu J, Shlomchik MJ, Emerson SG: Prevention of graft versus host disease by inactivation of host antigen-presenting cells. Science 1999, 285:412-415.

6. Le Blanc K, Frassoni F, Ball L, Locatelli F, Roelofs H, Lewis I, Lanino E, Sundberg B, Bernardo ME, Remberger M, Dini G, Egeler RM, Bacigalupo A, Fibbe W, Ringdén O; Developmental Committee of the European Group for Blood and Marrow Transplantation: Mesenchymal stem cells for treatment of steroidresistant, severe, acute graft-versus-host disease: a phase II study. Lancet 2008, 371:1579-1586

7. Garcia-Olmo D, Garcia-Arranz M, Herreros D, Pascual I, Peiro C, RodriguezMontes JA: A phase I clinical trial of the treatment of Crohn's fistula by adipose mesenchymal stem cell transplantation. Dis Colon Rectum 2005, 48:1416-1423.

8. Djouad F, Fritz V, Apparailly F, Louis-Plence P, Bony C, Sany J, Jorgensen C, Noël $D$ : Reversal of the immunosuppressive properties of mesenchymal stem cells by tumor necrosis factor alpha in collagen-induced arthritis. Arthritis Rheum 2005, 52:1595-1603.

9. Flierman R, Witteveen HJ, van der Voort El, Huizinga TW, de Vries RR, Fibbe WE, Toes RE, van Laar JM: Control of systemic B cell-mediated autoimmune disease by nonmyeloablative conditioning and major histocompatibility complex-mismatched allogeneic bone marrow transplantation. Blood 2005, 105:2991-2994.

10. Carrion F, Nova E, Ruiz C, Diaz F, Inostroza C, Rojo D, Mönckeberg G, Figueroa FE: Autologous mesenchymal stem cell treatment increased T regulatory cells with no effect on disease activity in two systemic lupus erythematosus patients. Lupus 2010, 19:317-322.

11. Christopeit M, Schendel M, Foll J, Muller LP, Keysser G, Behre G: Marked improvement of severe progressive systemic sclerosis after transplantation of mesenchymal stem cells from an allogeneic haploidentical-related donor mediated by ligation of CD137L. Leukemia 2008, 22:1062-1064.

doi:10.1186/ar3036

Cite this article as: Scherer HU, et al.: Mesenchymal stem cells in autoimmune diseases: hype or hope? Arthritis Research \& Therapy 2010,

12:126. 